\title{
A instrumentalização da csa (comunidade que sustenta a agricultura) para a construção de um novo conceito de consumo responsável através do princípio constitucional da solidariedade
}

\author{
The instrumentalization of csa (community that sustains \\ agriculture) for the construction of a new concept of \\ responsible consumption through the constitutional \\ principle of solidarity
}

iD Bárbara Michele Morais Kunde ${ }^{1}$

iD Jorge Renato dos Reis²

Resumo: A dignidade da pessoa humana é princípio basilar do ordenamento jurídico brasileiro, e, aliada ao princípio da solidariedade, que expressa o dever jurídico de se alcançar uma sociedade mais justa, livre e solidária, encontra terreno fértil nas denominadas Comunidades que Sustentam a Agricultura. Tais associações espelham relações mais humanas porque calcadas no consumo sustentável, além do compromisso de cooperação mútua para que todos permaneçam integrantes da cadeia produtiva, assegurando a autorrealização de cada uma das partes

\footnotetext{
1 Mestranda em Direito pelo Programa de Pós-Graduação em Direito - Mestrado e Doutorado da Universidade de Santa Cruz do Sul - UNISC. Bolsista da CAPES. Especialista em Direito Ambiental pela Universidade Luterana do Brasil - ULBRA. Graduada em Direito pela Universidade do Vale do Rio do Sinos - UNISINOS. Integrante do Grupo de Pesquisas "Intersecções Jurídicas entre o Público e o Privado - Constitucionalização do Direito Privado", vinculado ao PPGD da UNISC, coordenado pelo Prof. Pós-Doutor Jorge Renato dos Reis.

2 Pós-Doutor pela Università Degli Studi di Salerno-Itália com bolsa CAPES. Doutor pela Universidade do Vale do Rio dos Sinos-UNISINOS. Mestre em Desenvolvimento Regional pela Universidade de Santa Cruz do Sul-UNISC. Especialista em Direito Privado pela Universidade de Santa Cruz do Sul-UNISC. Graduado em Direito pelas Faculdades Integradas de Santa Cruz do Sul-FISC. Professor e pesquisador do Programa de Pós-Graduação Stricto-Sensu-Mestrado e Doutorado em Direito da UNISC, onde foi coordenador de 2004 a 2011. Professor na graduação da UNISC. Professor de cursos de Pós-Graduação Lato-Sensu em diversas universidades do país. É advogado atuante.
} 
A instrumentalização da csa (comunidade que sustenta a agricultura) para a construção... Bárbara Michele Morais Kunde • Jorge Renato dos Reis

envolvidas. Assim, o problema a ser enfrentado é: como o princípio da solidariedade, eleito como paradigma no âmbito da comunidade que sustenta a agricultura (CSA), contribui para o consumo responsável e a humanização das relações privadas? Para responder ao problema, a investigação empregou o método de abordagem dedutivo, e o método de procedimento monográfico, utilizando a pesquisa bibliográfica e documental. Ao final, conclui-se que somente a sociedade norteada pelo bem comum, em que se realize a dignidade individual voltada à consagração do grupo social mais pacífico e harmônico estará cumprindo o objetivo constitucional estabelecido no artigo terceiro.

Palavras-chaves: Comunidade que sustenta a agricultura. Principio da solidariedade. Responsabilidade.

Abstract: The dignity of the human person is the basic principle of the Brazilian legal system, and, together with the principle of solidarity, which expresses the legal duty to achieve a more just, free and supportive society, finds fertile ground in the so-called Communities that Sustain Agriculture. Such associations mirror more human relations because they are based on sustainable consumption, in addition to the commitment to mutual cooperation so that all remain members of the production chain, ensuring the self-realization of each of the parties involved. Thus, the problem to be faced is: how does the principle of solidarity, elected as a paradigm within the community that sustains agriculture (CSA), contribute to responsible consumption and the humanization of private relations? To answer the problem, the investigation used the method of deductive approach, and the monographic procedure method, using bibliographic and documentary research. In the end, it is concluded that only society based on the common good, in which the individual dignity aimed at the consecration of the most peaceful and harmonious social group will be fulfilling the constitutional objective established in article three.

Keywords: Community that supports agriculture. Principle of solidarity. Responsibility.

Data de submissão do artigo: Abril de 2019

Data de aceite do artigo: Junho de 2021 
A instrumentalização da csa (comunidade que sustenta a agricultura) para a construção...

\section{Introdução}

A Constituição Federal de 1988 trouxe inovações quanto à ordem jurídica, assumindo um papel ampliado no ordenamento jurídico brasileiro, e em vista de sua potencialidade, pode-se afirmar que desde então vem tomando a forma de um repositório geral de esperanças na construção de uma sociedade mais bem desenvolvida, calcada em bases de justiça e solidariedade.

Nesse cenário, ao mesmo tempo em que afirmou a sua normatividade, a Constituição manteve a tradição de indicar as estruturas do Estado, inovando, por outro lado, ao trazer definições valorativas e ideológicas, como se depreende de seu Preâmbulo, que traz a liberdade, a segurança, o bem-estar, o desenvolvimento e a justiça, entre outros, como valores de uma sociedade idealizada para ser fraterna, pluralista e desprovida de preconceitos.

Sendo reconhecida pelo seu poder norteador, tem o efeito de dimensionar os comportamentos futuros de todos aqueles que estão sob o seu manto, independentemente de ideologias políticas ou grupos que transitoriamente ocupam o poder. Por esse motivo, compromissa toda a sociedade a assumir como objetivo fundamental da República brasileira a construção de uma sociedade mais justa, livre e solidária.

Diante desse quadro, a escolha do tema torna-se relevante porque a partir desse novo paradigma em que a dignidade humana se torna o epicentro em uma sociedade constituída de relações altamente complexas, exige a atenção e o compromisso com a concretização dos direitos fundamentais. É por esta razão que o comando constitucional demanda a ação do Estado e da sociedade no sentido de buscar a erradicação da pobreza e diminuição das desigualdades sociais e regionais, bem como promover o bem comum, o que somente se alcança através da vivência fraterna em sociedade. Assim, considerando-se este contexto o problema a ser enfrentado é: como o princípio da solidariedade, eleito como paradigma aplicado no âmbito da comunidade que sustenta a agricul- 
A instrumentalização da csa (comunidade que sustenta a agricultura) para a construção... Bárbara Michele Morais Kunde • Jorge Renato dos Reis

tura, contribui para o consumo responsável e a humanização das relações privadas?

O objetivo geral da pesquisa é analisar este novo modelo de associação nas relações privadas, e seu papel na formação de um mercado de consumo sustentável com vistas ao bem comum sob o paradigma do princípio constitucional da solidariedade. Para responder ao problema, a investigação empregou o método de abordagem dedutivo, e o método de procedimento monográfico, utilizando a pesquisa bibliográfica e documental.

A fim de possibilitar uma melhor compreensão, o trabalho será dividido em três partes. Na primeira parte, a presente pesquisa busca estabelecer um marco teórico quanto à tutela da dignidade da pessoa humana como ponto de partida das relações privadas, que amplia seus horizontes para além das partes envolvidas e demonstra o compromisso responsável com todo um sistema contratual. Igualmente enfatizará o caráter essencial deste princípio como mecanismo de concretização dos direitos fundamentais concretizando o desiderato constitucional.

Em um segundo momento será analisada a formação e os princípios da comunidade que sustenta a agricultura (CSA) e seu papel no mercado de consumo responsável, em que o lucro monetário perde seu protagonismo e cede espaço ao ganho social mediante o envolvimento de várias pessoas, seja na produção, seja no consumo dos produtos.

Feita a devida investigação, a terceira parte será dedicada ao princípio da solidariedade para demonstrar que ele se revela como vetor de concretização dos direitos constitucionalmente assegurados. Entretanto, para que os direitos fundamentais sejam concretizados e componham a sociedade mais justa, livre e solidária, as relações devem exceder a um compromisso moral para alcançar o patamar de dever jurídico. Desse modo, para que haja a proteção e defesa dos direitos fundamentais, notadamente os insculpidos na Constituição de 1988, é preciso compreender a dimensão do princípio da solidariedade de molde a lhe dar a maior amplitude 
A instrumentalização da csa (comunidade que sustenta a agricultura) para a construção...

Bárbara Michele Morais Kunde • Jorge Renato dos Reis

possível como mecanismo de contribuição de cada indivíduo voltada à realização da dignidade humana, compreendida como a do corpo social.

\section{0 ponto de partida: a tutela constitucional da pessoa humana a balizar interesses jurídicos socialmente rele- vantes na esfera privada}

O princípio da dignidade da pessoa humana é remodelador das estruturas da dogmática do Direito Civil brasileiro, promovendo a necessária ligação entre as situações jurídicas patrimoniais à realidade existencial preconizada pela Constituição Federal de 1988.

No esteio de promover a inclusão social, dando seguimento ao dever constitucional de construir uma sociedade mais livre, justa e solidária, a dignidade é um elo necessário neste compromisso partilhado pelo legislador ordinário, o intérprete da lei e o juiz.

Nesse quadro, a releitura do Direito Civil à luz da Constituição Federal revela o indispensável processo de transformação social guiando a autonomia privada na incursão de valores para além do aspecto patrimonial. Este cenário evidencia que o indivíduo ou o sujeito, matizados de valores existenciais, passam a ser tratados como pessoa humana, para cuja promoção se volta toda a ordem jurídica.

Após 30 anos da Constituição brasileira, ainda se busca a efetivação dos valores existenciais, permanecendo a exigência de se considerar a pessoa a partir de dados da realidade, migrando do plano metafísico para o material, inclusive no que tange ao reconhecimento das diferenças que justificam uma hermenêutica contextual destinada à sua tutela integral.

Com arrimo nesta construção da pessoa, impostergável a compatibilização entre a igualdade formal do sujeito (libertadora de preconceitos) e a igualdade substancial da pessoa (protetora 
A instrumentalização da csa (comunidade que sustenta a agricultura) para a construção...

das vulnerabilidades), suscitando a construção da norma jurídica em conformidade com esta nossa leitura TEPEDINO, 2016, p. 19).

Em face da realidade mutante e transformadora, não se pode mais manter o entendimento puramente conceitual da dignidade dissociado da existência de um homem agora integrado à sociedade, sob pena de não se apreender a realidade histórica atual. Neste contexto, notabiliza-se a necessidade de se realizar uma hermenêutica contextual que ruma à concretização do compromisso constitucional da sociedade.

Neste sentido, é imprescindível que a ideologia essencialmente individualista seja deixada no marco histórico dos séculos XIX e XX, pois o que se imaginava possibilitar riquezas e desenvolvimento tanto das pessoas quanto das nações, mais acirrou as desigualdades entre seus (isolados) integrantes.

Como consequência, o profundo processo de transformação iniciado já a partir da Primeira Guerra Mundial produziu forte impacto nas estruturas das relações envolvendo contrato e propriedade, elevando o agir individual a elemento interagente, ao invés de elemento primordial. Significa que a rejeição da ideia da invasão da esfera pública sobre a privada passou a ser conceituada como uma transformação estrutural do que seja o Direito Civil, ampliada ao ponto de "abrigar, na tutela das atividades e dos interesses da pessoa humana, técnicas e instrumentos tradicionalmente próprios do direito público, como, por exemplo, a aplicação direta das normas constitucionais nas relações jurídicas de direito privado" (MORAES, 2010, p. 7).

Centrando-se o ordenamento na dignidade não apenas como direito, mas sim como princípio-valor, o ambiente econômico é campo de manifestação da mesma. Desse modo, a atividade econômica deixa de ser vista como fator de legitimidade da dignidade para assumir sua função de ambiente onde aquela possa ser manifestada. O contrato, portanto, se revela, nesta conjuntura, como importante ferramenta que não pode ficar alheia aos interesses coletivos sob o argumento de se proteger aa pessoa (COSTA; CASTRO, 2016, p. 460). 
A instrumentalização da csa (comunidade que sustenta a agricultura) para a construção...

Porém, tal circunstância não anula a autonomia do indivíduo, que permanece assegurada, mas com um contorno mais adequado ao contexto histórico, antropológico e ideológico voltado ao coletivo, o que muitas vezes vai de encontro com a primazia que a doutrina moderna ainda atribui à vontade, destacadamente no campo do Direito Privado.

Seguindo a orientação constitucional, as relações sociais passam a ser protegidas pelo Direito sob esta nova égide, e por isso as partes envolvidas deixam de ser as únicas peças importantes, eis que os negócios jurídicos produzem também efeitos mediatos que envolvem terceiros, efeitos que extrapolam a esfera patrimonial e trazem também conteúdo existencial, pois que a autodeterminação da pessoa excede este conteúdo. E como já afirmado acima, a atividade econômica não deve ser apenas fonte legitimadora da dignidade da pessoa, mas sim o ambiente onde ela deverá se materializar.

Nessa toada, as decisões não devem se subsumir apenas às partes diretamente envolvidas, de modo que seus efeitos jurídicos irão produzir fatos jurídicos na esfera alheia, pois que se o objetivo constitucional é a construção de uma sociedade fraterna, caracterizando-se este como desiderato comum a todos, deve haver também um correspondente esforço comum. Diante de tais alterações o Direito Privado deixou de ser o primado da vontade individual, assim como o Direito Público não mais se inspira na subordinação do cidadão.

Partindo-se desse modelo que tem como referencial principiológico a dignidade da pessoa humana no contexto de uma sociedade caracterizada por avanços tecnológicos e científicos, que redundam em consequências também para as gerações futuras, a ética da responsabilidade é outro fator a ser analisado no presente artigo.

Cabe, então, trazer à baila o conceito de responsabilidade que cada um dos brasileiros tem para com a comunidade que integra 
A instrumentalização da csa (comunidade que sustenta a agricultura) para a construção... Bárbara Michele Morais Kunde • Jorge Renato dos Reis

e como parte de uma nação ocupada em minimizar as diferenças materiais e sociais, buscando a maior igualdade possível.

Todavia, não se trata apenas do conceito clássico de responsabilidade, que atribui ao indivíduo o encargo das condutas realizadas. Vale destacar que há um imperativo ético no sentido de compromissar a pessoa por meio de um dever de agir em benefício de outra e também das demais que compõem a coletividade.

Hans Jonas (2006, p. 47) complementa o imperativo categórico de Kant (2004, p. 51)33, atrelando o agir humano a um exercício geral da comunidade, no sentido de que a lógica de "poder" e "não poder" expresse compatibilidade ou incompatibilidade, e não uma aprovação ou reprovação moral.

Para tanto, o autor propõe um novo tipo de agir humano: "Aja de modo a que os efeitos da tua ação sejam compatíveis com a permanência de uma autêntica vida humana sobre a Terra", ou expresso negativamente: "Aja de modo a que os efeitos da tua ação não sejam destrutivos para a possibilidade futura de uma tal vida" (JONAS, 2006, p. 47-48).

A fim de se compreender melhor o pensamento jonasiano, é preciso relembrar que enquanto Kant exortava o indivíduo a se voltar para si, ponderando se aquilo que desejasse para si fosse transformado em uma lei geral haveria coerência ou incoerência, o que orientaria a escolha privada, Jonas amplia a relevância da escolha ao considerar principalmente os seus efeitos. Segundo ele este agir é o que torna a escolha efetivamente lei geral para todos e promove consequências reais, acrescendo ao horizonte moral de Kant o pressuposto temporal, o que consubstancia um futuro previsível e concreto.

No âmbito da teoria deste filósofo há um dever incondicional de observar a responsabilidade, compartilhada, de promover a existência humana, implicando, portanto, deveres para as gerações atuais e futuras. E aqui está o ponto de diferença entre Kant e Jonas: aquele considera o ser humano em relação aos demais,

$\overline{3 \text { Kant afirmava: "Aja }}$ de modo que tu também possas querer que tua máxima se torne lei geral". 
A instrumentalização da csa (comunidade que sustenta a agricultura) para a construção... Bárbara Michele Morais Kunde • Jorge Renato dos Reis

porém tendo como ponto de partida a si próprio, este soma o atributo temporal à responsabilidade e remete as consequências dos atos individuais para o futuro, considerando não apenas a humanidade atual, mas a que está por vir, cuja existência digna depende do presente vivido responsavelmente.

Não se trata mais de um "dever ser", mas sim um "ser" ainda que a consequência disso não tenha chegado, mas certamente assim será, como tem ocorrido ao longo do desenvolvimento da humanidade, pois atos pretéritos foram o campo fértil para as conquistas atuais.

O interesse meramente utilitário está superado, pois a condição global da vida humana e o futuro distante não estão mais apartados, exigindo uma nova concepção de vida por meio da releitura de direitos e deveres.

Como exposto, a repersonalização do Direito Privado, lançando o indivíduo ao topo do sistema de proteção, o atual Código Civil pátrio também passou a regular os principais institutos civilísticos como a propriedade e os contratos, o que se passará a analisar mais detidamente no âmbito das comunidades de sustentação da agricultura.

\section{A comunidade que sustenta a agricultura (CSA) como novo modelo de associação nas relações privadas do mercado de consumo responsável}

Muito embora tenha a Constituição salvaguardado a propriedade, a liberdade, segurança e igualdade, o compromisso mais humanista, decorrente do desprendimento da ótica essencialmente liberal, avançou à esfera de todas as classes, exigindo a conciliação de interesses e pacificação de conflitos entre as gentes. Isto porque o paradigma até então consolidado se fragilizou, reclamando alternativas substitutivas através de um esforço crítico de discussão 
A instrumentalização da csa (comunidade que sustenta a agricultura) para a construção...

de seus pressupostos que até então eram aceitos pelos cientistas (FARIA, 1988, p. 21).

Desde o início da vigência do Código Civil de 2002 a doutrina procurou fincar marcos concretos de aplicação para conferir a máxima eficácia social de seus preceitos privados mantendo os valores constitucionais alicerçados no ordenamento jurídico.

Como já sabido, a partir do Código Civil foram definidos novos valores e parâmetros hermenêuticos a servirem de preceitos e referência interpretativa-axiológica das demais disposições. O Código passou a pautar, através de cláusulas gerais, as relações privadas, cabendo ao intérprete realizar a integração de sua conduta ao sistema jurídico sob o arrimo dos princípios constitucionais.

Em virtude da necessidade de tratamento adequado ao fenômeno da massificação contratual e das partes vulneráveis envolvidas, os princípios e as cláusulas gerais transfiguraram-se em ferramentas poderosas para a consecução da justiça social, diretrizes essenciais nas relações interprivadas (AQUINO JÚNIOR, 2019, p. 419).

Como já analisado, o reconhecimento de direitos individuais e garantias fundamentais são primordiais na realização humana, porém a sua normatização se mostrou insuficiente para a efetiva fruição, já que condições mínimas devem ser asseguradas para a existência de cada ser humano.

Insta destacar que esta transformação que se vem consolidando há pelo menos duas décadas, não depende de meros retoques teóricos ou ajustes conceituais como fatores de desconstrução dos dogmas contratuais mantidos, pois não basta "destruir" conceitos, é preciso atrelar esta desconstrução à reconstrução para uma otimização do Direito Civil contemporâneo.

Nesse quadrante, os princípios sociais (princípio da boa-fé objetiva, da função social do contrato e equivalência material do contrato) não têm o condão de neutralizar os princípios clássicos liberais (pacta sunt servanda, autonomia privada e eficácia subsumida aos contratantes) uma vez que estão regrados não como pa- 
A instrumentalização da csa (comunidade que sustenta a agricultura) para a construção...

râmetros para estabelecer antagonismo entre eles, mas sim uma necessária harmonização.

Muito embora a função social do contrato não esteja prevista na Constituição Federal, o exercício da atividade econômica está condicionado à observância do princípio, pois o resultado interpretativo deve resultar de "um processo argumentativo não apenas lógico, mas axiológico, inspirado no princípio da dignidade da pessoa humana como prioritário no confronto com os interesses superiores do Estado e do mercado" (LÔBO, 2009, p. 37).

Assentadas as bases constitucionais, parte-se para a análise mais específica da esfera privada, tencionando analisar a eficácia dos direitos fundamentais nas relações jurídico-privadas.

A liberdade é pressuposto de vivência do ser humano, e, na contemporaneidade, o ambiente político articula tanto as liberdades individuais (opinião pública livre, tolerância, direito à diferença), quanto a liberdade do cidadão (voz ativa no espaço público) para evitar que a democracia não passe de um simulacro (SARMENTO, 2006, p. 146).

Além disso, enfatiza Daniel Sarmento (2006, p. 154) que a liberdade é esvaziada quando as condições materiais mínimas para o seu exercício não são asseguradas aos seus titulares.

Que valor determinante na promoção da dignidade humana tem a liberdade formal? A autonomia privada traveste-se como um dos componentes primordiais da liberdade, consubstanciada no poder individual de concretizar seus projetos espirituais, articulada a direitos de terceiros e valores relativos à comunidade.

A liberdade, pois, é a regra, e na busca desta autorrealização, o ser humano procura estabelecer as bases materiais para a sua vida - propriedade, bens de consumo -, encontrando na atividade econômica o ambiente propício para tanto, solidificando-se como um dos grandes pilares nas situações concretas.

Nesse prisma, assegura-se o exercício livre de qualquer trabalho, profissão ou ofício, desde que atendidas as qualificações 
A instrumentalização da csa (comunidade que sustenta a agricultura) para a construção...

profissionais que a lei exigir (artigo $5^{\circ}$, inciso XIII) e realizados os ajustes recíprocos nas situações concretas.

O texto constitucional prossegue, no artigo 170, estabelecendo como fundamento da ordem econômica a livre iniciativa e a valorização do trabalho, seguindo, entre outros, o princípio da livre concorrência, premissas fundamentais do modelo de ordem econômica capitalista adotado pela Constituição brasileira. Significa, portanto, como assevera José Afonso da Silva (1996, p. 720) “que a Constituição consagra uma economia de mercado, de natureza capitalista, pois a iniciativa é um princípio básico da ordem capitalista."

Ao mesmo tempo está incluído, entre os objetivos da República a redução das desigualdades sociais e regionais que será alcançada por meio da igualdade substancial e justiça distributiva, que fazem com que a função social da propriedade seja o conteúdo determinante a nortear a atividade, estabelecendo a sua funcionalização articulada aos princípios constitucionais (AQUINO JÚNIOR, 2019, p. 425).

Nesse rumo, compromissada que está a sociedade com o desenvolvimento digno de todos, é que se analisará o que são as Comunidades que Sustentam a Agricultura (CSA), sua origem e finalidades, instituindo-se as mesmas como um relevante instrumento de realização de justiça social equilibrada entre o mercado e o interesse privado, harmonizada pelo bem comum.

Inicialmente é preciso dar os contornos do que seja uma CSA para que se possa estabelecer a sua relevância no plano do Direito Privado a produzir relevantes repercussões na esfera coletiva.

As CSA's têm sua origem no Japão, na década de 1970, como solução ao desastre de Minamata, problema gerado pela contaminação ambiental por mercúrio, que levou as donas de casa a comprar seus alimentos diretamente dos agricultores orgânicos, valorizando a iniciativa desta mão-de-obra. O intento alcançou tanto êxito que ganhou abrangência internacional e, muito embora vertido por fatores distintos nos mais diversos locais, ainda 
A instrumentalização da csa (comunidade que sustenta a agricultura) para a construção... Bárbara Michele Morais Kunde • Jorge Renato dos Reis

hoje mantém a ideia originária que é o apoio da comunidade à agricultura4.

Nesse sistema o agricultor prescinde de intermediários para a comercialização dos produtos que cultiva, pois se associa a pessoas interessadas em compartilhar a organização de sua produção. Planejam-se, então, os custos com a produção e a sua divisão para o necessário rateio, para que então se promova a distribuição dos produtos entre todos os associados. Por meio deste modelo todos os envolvidos se voltam ao bem comum: o agricultor tem sua renda garantida, e o consumidor tem acesso a produtos de melhor qualidade, objetivos fundados no respeito ao meio ambiente e na valorização da produção local.

A ideologia das CSA's é a congregação da solidariedade através do apoio mútuo de seus associados, que resulta no cultivo de produtos orgânicos voltados à sustentabilidade como resposta à demanda cada vez maior pela alimentação saudável. Por isso são criadas as "cotas", que são cestas compostas por legumes, verduras e frutas entregues semanalmente nos "pontos de convivência", locais de encontro entre os agricultores e coagricultores, que além da aquisição dos produtos, promovem o comprometimento e amizade entre todos 5 .

Importante ressaltar que a CSA tem com principal papel identificar produtores e consumidores que compartilham este ideal de produção e consumo, concretizando-o pela formação de núcleos gestores para organização de locais, horários e logística para que os alimentos cheguem às pessoas. Pela simplicidade do sistema calcado no auxílio mútuo, as comunidades podem ser apoiadas por qualquer entidade, e os pontos de encontro podem ser realizados em escolas, entidades religiosas, espaços públicos ou de qualquer organização da sociedade civil.

Voltada ao bem comum, a comunidade espelha a solidariedade, pois alimenta um mercado de consumo responsável pois seu

4 Informações extraídas do site da AS-PTA - Agricultura familiar e ecologia, disponível em: <http://aspta.org.br/wp-content/ uploads/2015/10/Agriculturas_V12N2_Artigo4.pdf>. Acesso em 25 fev. 2019.

50 envolvimento é tal que não raras vezes o interesse dos consumidores desperta-lhes o desejo de realizar trabalho voluntário na propriedade rural, tornando-o mais um fator positivo nesta convivência. 
A instrumentalização da csa (comunidade que sustenta a agricultura) para a construção...

objetivo fundante é a produção ecológica e economicamente sustentável, passando, portanto, pela eliminação dos atravessadores, grandes responsáveis pela valorização dos interesses preponderantemente econômicos.

É significativo destacar que o princípio da solidariedade se infiltra nas relações interprivadas construídas a partir de mútuas relações de cooperação, norteando os envolvidos no respeito recíproco das individualidades e dignidade de cada qual. Neste contexto as relações sociais passarão a atender melhor às necessidades existenciais dos contratantes.

Como bem ressalta Aquino Júnior (2019, p. 432), cotejando-se o bem e a pessoa, as soluções concretas oxigenarão a tensão dialética entre a autonomia e a dignidade, harmonizando a liberdade individual e os valores coletivos da justiça social e da solidariedade.

A essência da CSA pressupõe, como já afirmado, apoio mútuo em que o agricultor sabe que pode contar com o grupo, o que viabiliza e valoriza a sua atividade, assim como o grupo sabe que terá uma oferta de produtos saudáveis produzidos com segurança e respeito ao meio ambiente.

Além disso, contando com consumidores certos, os agricultores têm a certeza de que sua produção será absorvida e, portanto, o apoio financeiro também se materializa, assim como a segurança de que os alimentos serão consumidos e o desperdício será evitado.

Logo, a CSA é realmente o palco para se produzir relações humanizadas pelo interesse no bem comum, pois não basta que este seja um desejo, é preciso o empenho de todos para que seja alcançado.

Com o objetivo de se alcançar efetivamente esta nova realidade, passaremos a analisar o princípio constitucional da solidariedade como relevante vetor da concretização da dignidade humana através da comunidade que sustenta a agricultura. 


\section{A solidariedade como paradigma do consumo res- ponsável e a transformação das relações humanas nas CSA's}

Diante de novas perspectivas de interpretação dos direitos, seja do ponto de vista de sua extensão, seja considerando todas as contingências do mundo cosmopolita, o padrão até então assentado deixou de responder eficazmente às necessidades humanas. A crise atual pressupõe reflexões voltadas à construção de um novo modelo garantidor dos direitos fundamentais que leve em conta o mercado como um espaço de oportunidades para o desenvolvimento do significado da vida.

Há a necessidade de uma nova forma de pensar, adequada aos novos tempos, que exigem muito mais do que verdades morais, universais ou o bem comum da humanidade em abstrato, sob pena de se correr sério risco de não se alcançar as soluções possíveis.

Ao se tratar do campo das relações contratuais relevante destacar que o Código Civil consagrou uma das mais importantes modificações principiológicas que é exigir do contrato o cumprimento de sua função social ${ }^{6}$. Inicialmente tal disposição era utilizada como limitadora da livre iniciativa privada, cuja premissa básica era total liberdade entre as partes e a abstração do conjunto. Entretanto, como já se destacou, com a evolução dos conceitos e a sua premência na realidade prática, hoje já se pode afirmar que o princípio alcançou status de ponto de partida, ou seja, deixou de ser um limitador e se tornou uma diretriz ético-legal das relações contratuais.

No caso da CSA tais valores se infiltram na essência do contrato e as comunidades podem ser definidas como instrumentos de realização existencial, pois otimizam as oportunidades individuais e promovem um desenvolvimento interdependente e plenamente solidário.

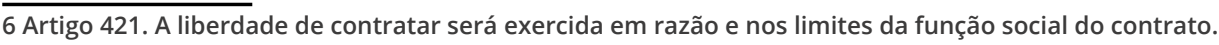


A instrumentalização da csa (comunidade que sustenta a agricultura) para a construção... Bárbara Michele Morais Kunde • Jorge Renato dos Reis

Tal situação requer a análise sob dois aspectos: o econômico, relativamente às partes envolvidas, e de sustentabilidade, considerando-se as futuras gerações, eis que se está diante de um contrato voltado ao desenvolvimento humano sustentável.

Nesse cenário, a atuação do princípio da solidariedade impõe uma conduta que respeita a liberdade contratual desde que observado o equilíbrio no poder de barganha entre as partes, e para além disso, ainda tutela direitos de terceiros estranhos ao contrato. Para tanto, é necessário não perder de vista que o mercado existe enquanto espaço de interação social e coletiva, capaz de produzir efeitos na esfera individual a depender da consciência de responsabilidade de cada um. O mercado, portanto, além de ser um fato social, pode ser regulado por normas jurídicas, o que é o caso do instituto em análise, pois o seu funcionamento adequado e eficaz depende de outros fatores que vão além da autonomia privada.

Sem dúvidas que o Estado deve intervir nas relações para dar eficácia ao princípio da função social do contrato através de um direcionamento para uma distribuição melhor das riquezas. Todavia, tal desiderato não afasta os particulares de também cumprirem sua tarefa nesta complexa relação, e aí reside o dever jurídico de solidariedade.

Necessário, pois, fincar novos fundamentos para uma convicção a ser partilhada coletivamente no sentido de não mais questionar se a Constituição contempla ou não direitos, discussão, aliás, já superada. O debate deve permear o campo das garantias destes mesmos direitos, quadro que traz à evidência a relevância do papel do princípio da solidariedade.

Não se pode ignorar que a construção da sociedade justa e livre ${ }^{7}$ exige a superação da tradicional submissão do ordenamento jurídico à propriedade, à liberdade individual, à economia; os moldes de sua tutela ampliam-se com o acréscimo do anseio pela

\footnotetext{
7 Constituição Federal. Art. $3^{\circ}$. Constituem objetivos fundamentais da República Federativa do Brasil:

I - construir uma sociedade livre, justa e solidária;

II - garantir o desenvolvimento nacional;

III - erradicar a pobreza e a marginalização e reduzir as desigualdades sociais e regionais;

IV - promover o bem de todos, sem preconceitos de origem, raça, sexo, cor, idade e quaisquer outras formas de discriminação.
} 
A instrumentalização da csa (comunidade que sustenta a agricultura) para a construção...

concretização da dignidade humana, a ser alcançada pelo dever jurídico de solidariedade.

Alerte-se, porém, que tal premissa enfrenta maior dificuldade para sua afirmação concreta porque afeta a liberdade em sua visão individualista, justamente porque encerra a ideia de uma justiça distributiva que naturalmente culmina em alteração de status quo, ferindo setores privilegiados da sociedade que não têm interesse nas mudanças.

A sociedade justa, livre e solidária é direito de todo o corpo coletivo e não de cada um separadamente, e por isso a aplicação do Direito contemporâneo se dá mediante relações pautadas por um fluir, de modo que ao se aplicar o Direito Privado, por exemplo, se está a aplicar a própria Constituição (SARLET, 2005, p. 341).

As relações entre pessoa, Estado e sociedade devem ser permeadas pela responsabilidade de todos por todos, traduzindo-se como tarefa da sociedade no reconhecimento da dignidade do outro, superando a visão individualista de bem (DI LORENZO, 2010, p. 18).

Nessa linha de pensamento Comparato (2006, p. 577) diferencia liberdade, igualdade e solidariedade, afirmando que esta unifica, convocando todas as pessoas a defenderem algo que Ihes é comum, enquanto liberdade e igualdade promovem a reivindicação do que lhes é próprio, pois as colocam umas diante das outras.

O princípio da responsabilidade, como já enfatizado, não preconiza a responsabilidade objetiva, mas sim a formação subjetiva da autodeterminação da pessoa, isto é, clama o novo imperativo a coerência dos efeitos finais do ato para a continuidade da atividade humana no futuro (JONAS, 2006, p. 49)

As partes componentes da CSA são movidas por este "olhar para o futuro", porque além de constituírem uma relação contratual (essencialmente privada), promovem também a humanização das relações pessoais, ampliando o rol de envolvidos pelo sentimento mútuo de prover as necessidades materiais respeitando e satisfazendo as necessidades de cada parte. Tal desiderato induz 
A instrumentalização da csa (comunidade que sustenta a agricultura) para a construção...

o consumo responsável na medida em que os envolvidos mantêm o contrato para que as relações humanas permaneçam, no lugar do preço, consolida-se o apreço.

Emerge, então, o fato de a solidariedade se cristalizar no ordenamento jurídico brasileiro como contorno de proteção dos interesses difusos, ambicionando uma justiça social distributiva.

Em meio à tradição liberal, relevante destacar que o princípio da solidariedade não se contrapõe à liberdade, ele delineia a autonomia privada, isto porque os direitos fundamentais, sejam de que dimensão forem, são complementares e não excludentes, o que também retira o caráter prima facie do princípio.

Na verdade, o princípio da solidariedade é regente das relações, consagrando-se como um balizador indispensável na ponderação entre os interesses envolvidos. Significa, pois, que havendo interesses contrapostos, a sociedade como um todo deve ser reverenciada, uma vez que condutas e comportamentos estão imbricados a consequências que atingirão um número indefinido de pessoas.

O valor jurídico-social da solidariedade como princípio constitucional desvela-se propulsor do desenvolvimento da sociedade brasileira porque instrumento de garantia dos direitos fundamentais, assim como aparelha substancialmente o dever fundamental de consumo sustentável.

Esta nova ótica significa que a economia de mercado impulsionada pelo lucro cede margem para que todos se beneficiem e que um maior número de pessoas tenha acesso pleno a estas novas condições. É, portanto, um investimento da sociedade em capital humano, já que se lucra menos para que o acesso ao produto e o consumo se amplie, e garante-se a compra do produto para que a cadeia de produção se mantenha viva.

Importante resgatar Hans Jonas (2006, p. 47) e sua teoria da responsabilidade que compatibiliza a ação individual com a sociedade ao afirmar que os efeitos da ação humana devem ser compatíveis com uma autêntica vida na Terra. Sob a égide da Constituição 
A instrumentalização da csa (comunidade que sustenta a agricultura) para a construção...

Federal brasileira a autêntica vida significa a realização da pessoa humana em seus propósitos, assegurando-lhe dignidade.

Nesse sentido, o princípio da solidariedade inspira novos contornos ao consumo sustentável porque além do resultado imediato, que é a concretização do direito fundamental à livre iniciativa e o lucro, resultado capitalista advindo dela, também propicia o dever fundamental de contribuir para que o outro goze dos direitos fundamentais de que é titular.

A economia de mercado não pode constituir um óbice à tarefa que o Direito tem de fornecer respostas adequadas e justas às diferenças encontradas na sociedade contemporânea, para isso mister a utilização do princípio da solidariedade na promoção da confiança em relação aos demais parceiros contratuais, o que reflete no desempenho de todos.

Proteger a confiança significa acreditar na atuação dos outros parceiros contratuais, o que possui reflexos no desempenho de todos, contribuindo para que as condutas na sociedade e no mercado convirjam par ao nascimento de expectativas legítimas naqueles em que a confiança é despertada (AQUINO JÚNIOR, 2019, p. 435).

Neste sentido, o princípio da solidariedade enseja uma equidade contratual onde todos os riscos são partilhados para que o resultado final seja acessível a todos os envolvidos.

Com o nascimento da CSA a prática contratual não é apenas um ato de comércio e deixa de ser isolado para se tornar atividade integrante de uma rede ou sistema, pois somente quando há a cooperação do consumidor dos produtos cultivados é que a agricultura familiar é valorizada e preservada.

Somente o senso de responsabilidade é que leva o indivíduo a optar pelo pequeno produtor rural ao invés do supermercado, a primar pela agroecologia, a cultura preservada, a redução da pobreza, o desenvolvimento e o crescimento econômico com sustentabilidade. 
A instrumentalização da csa (comunidade que sustenta a agricultura) para a construção... Bárbara Michele Morais Kunde • Jorge Renato dos Reis

Ao fim e ao cabo, a CSA traz intrínseca a convivência solidária entre o campo e a cidade, entre o produtor e o consumidor que não são mais solitários, cada qual desempenhando um papel estanque, mas ao contrário, solidários em objetivos e ideais, o que reverte positivamente para todos.

\section{Considerações finais}

Estando todo o ordenamento jurídico albergado sob o manto constitucional que se apresenta como diretriz de interpretação de todas as normas jurídicas, o princípio da solidariedade opera como vetor de humanização da atividade interpretativa, agora com as lentes da dignidade da pessoa como parte de um todo, voltado a uma sociedade mais justa e livre.

As relações contratuais ainda sob a visão do positivismo oitocentista adotado pelo modelo liberal comprovaram a sua insuficiência para a construção de uma sociedade livre, justa e solidária, antes tornou-se mecanismo de segregação social.

Em matéria de relações privadas o contrato tornou-se também legitimador deste processo de profundas diferenças já que tradicionalmente denominado como "lei entre as partes". Entretanto, o anseio por novos paradigmas foi legitimado a partir da Constituição de 1988, que em seu artigo terceiro convoca todos os brasileiros a laborarem no sentido de erradicar a pobreza e, através do desenvolvimento nacional minimizar, as desigualdades sociais, contribuindo para o bem de todos.

Estas transformações ganham relevante instrumento, verdadeiro vetor de transformação, que é o princípio da solidariedade, ao ser a construção da sociedade solidária um dos objetivos da República.

Mais especificamente, voltando-se ao ponto de partida que tem como diretriz axiológica o princípio da dignidade da pessoa 
A instrumentalização da csa (comunidade que sustenta a agricultura) para a construção...

humana, surge uma nova construção voltada ao bem comum que são as comunidades que sustentam a agricultura (CSA).

Com o objetivo de alcançar relações seguras, seja para o produtor, que tem o mercado de consumo garantido pelos parceiros, seja para o consumidor que prioriza a aquisição do produto saudável, a cooperação é a chave mestra nesta associação.

Nesse contexto, a solidariedade, em sua perspectiva jurídica, se traduz como postura ativa em prol do bem comum, o que só se aufere em face de sua natureza principiológica. A sua eficácia somente se acentuará na medida em que todos se voltem à realização da fraternidade, ou seja, do estreitamento dos laços humanos, sob a perspectiva da coletividade e não apenas dos indivíduos.

Por meio de um agir responsável é que a conduta individual ganha contornos de coletivo, de modo que se passa a agir e pensar nas consequências que ela produz não apenas às partes envolvidas, mas na comunidade.

Por esta visão o princípio da solidariedade revela-se transformador das relações humanas porque compromissa todos através de um senso de responsabilidade social originado do dever de cooperação e ajuda mútua, que, conjuntamente, revigorarão o desiderato constitucional.

Conclui-se, portanto, que não só é possível, como imprescindível, utilizar-se do princípio da solidariedade no âmbito da comunidade que sustenta a agricultura tendo em vista a necessidade de um novo paradigma aplicável às relações privadas voltadas ao consumo responsável.

Isto porque a CSA consubstancia o objetivo primário da Constituição que estabelece um fim a ser atingido diverso daquele típico dos agentes livres do mercado.

Neste modelo, ambas as partes assumem deveres para que 0 resultado final possa ampliar direitos, que, ao fim e ao cabo, desaguam na realização da dignidade humana, traduzida na qualidade de vida, na produção sustentável de alimentos saudáveis, na oportunidade de renda e no compartilhamento de custos, diluindo-os 
A instrumentalização da csa (comunidade que sustenta a agricultura) para a construção... Bárbara Michele Morais Kunde • Jorge Renato dos Reis

entre todos para que o resultado final alcance feição positiva, proporcionando benefícios à comunidade.

Somente assim é que rumaremos a uma civilização solidária e mais justa calcada no consumo responsável não somente sob o ponto de vista ecológico, mas principalmente a partir de relações humanas transformadas.

\section{Referências}

AQUINO JÚNIOR, Geraldo Frazão de. O direito contratual e a marcha da constitucionalização entre ouriços e raposas. In: ERHARDT JÚNIOR, Marcos; CORTIANO JÚNIOR, Eroulths (Coord.). Transformações no Direito Privado nos 30 anos da Constituição: estudos em homenagem a Luiz Edson Fachin. Belo Horizonte: Fórum, 2019, p. 419-439.

BAGGIO, Antônio Maria. A redescoberta da fraternidade na época do "terceiro 1789", tradução de Durval Cordas, Iolanda Gaspar. In: BAGGIO, Antônio Maria (Org). O princípio esquecido: a fraternidade na reflexão atual das ciências políticas. São Paulo: Editora Cidade Nova, 2008, p. 7-24.

BASSO, Joaquim. O dever fundamental de produção agrária com sustentabilidade e segurança alimentar. Revista dos Tribunais Online, Thompson Reuters. https://www. academia.edu/10375523/O_dever_fundamental_de_produ\%C3\%A7\%C3\%A3o_agr\%C3\%A1ria_com_sustentabilidade_e_seguran\%C3\%A7a_alimentar. Acesso em 31 jan. 2018.

BRASIL. Constituição (1988). Constituição da República

Federativa do Brasil. Brasília, DF: Senado Federal, 1988. Disponível em < http://www.planalto. gov.br/ccivil_03/constituicao/constituicao.htm>. Acesso em: 11 jan 2019.

CARDOSO, Alenílton da Silva. Princípio da solidariedade: o paradigma ético do Direito contemporâneo. Ed. rev. e atual. São Paulo: Editora Ixtlan, 2014. 
A instrumentalização da csa (comunidade que sustenta a agricultura) para a construção...

COMPARATO, Fábio Konder. Ética: direito, moral e religião no mundo moderno. São Paulo: Companhia das Letras, 2006.

COSTA, André Brandão Nery; CASTRO, Raul Murad Ribeiro de. Notas sobre a influência de interesss extracontratuais socialmente relevantes no contrato. In: O Direito Civil entre o sujeito e a pessoa: estudos em homenagem ao professor Stefano Rodotà. TEPEDINO, Gustavo, TEIXIERA, Ana Carolina Brochado, ALMEIDA, Vitor (Coords.). Belo Horizonte: Fórum, 2016, p. 459-479.

DI LORENZO, Wanbert Gomes. Teoria do estado de solidariedade: da dignidade da pessoa humana aos seus princípios corolários. Rio de Janeiro: Elsevier, 2010.

FARIA, José Eduardo Soares. A noção de paradigma na Ciência do Direito: notas para uma crítica ao idealismo jurídico. In: FARIA, José Eduardo Soares (Org.). A crise do Direito em uma sociedade em mudança. Brasília: Editora da Universidade de Brasília, 1988.

JONAS, Hans. O Princípio Responsabilidade: ensaio de uma ética para a civilização tecnológica. Trad. Marijane Lisboa, Luiz Barros Montex. Rio de Janeiro: Contraponto. Ed. PUC-Rio, 2006.

KANT, Immanuel. Fundamentação da metafísica dos costumes e outros escritos. Sã Paulo: Martin Claret, 2004.

LÔBO, Paulo Luiz Netto. Direito Civil: parte geral. São Paulo: Saraiva, 2009.

MORAES, Maria Celina Bodin de. Na medida da pessoa humana: estudos de direito civil. $1^{\text {a }}$ reimp., Rio de Janeiro: Renovar, 2016. PEDRA, Adriano Sant'Ana, FREITAS, Rodrigo Cardoso. A função social da propriedade como um dever fundamental. Revista da Faculdade de Direito UFMG, Belo Horizonte, n. 66, pp. 53 - 74, jan./jun. 2015. 
A instrumentalização da csa (comunidade que sustenta a agricultura) para a construção... Bárbara Michele Morais Kunde • Jorge Renato dos Reis

REIS, Jorge Renato dos. A constitucionalização do Direito Privado: algumas considerações para análise. Revista Atos \& Fatos (Curso de Direito da Celer Faculdades), v. 1, p. 126-139, 2009.

SILVA, José Afonso da. Curso de Direito Constitucional Positivo. São Paulo: Malheiros, 1996.

SARLET, Ingo Wolfgang. A eficácia dos diretos fundamentais. $5^{a}$ ed. Porto Alegre: Livraria do Advogado, 2005.

SARMENTO, Daniel. Direitos fundamentais e relações privadas. 2. ed. Rio de Janeiro: Lúmen Júris, 2006.

SARMENTO, Daniel. Dignidade da pessoa humana: conteúdo, trajetórias e metodologia. 2. ed. Belo Horizonte: Fórum, 2016.

TEPEDINO, Gustavo. O papel atual da doutrina no Direito Civil entre o sujeito e a pessoa. In: 0 Direito Civil entre o sujeito e a pessoa: estudos em homenagem ao professor Stefano Rodotà. TEPEDINO, Gustavo, TEIXIERA, Ana Carolina Brochado, ALMEIDA, Vitor (Coords.). Belo Horizonte: Fórum, 2016, p. 17-38. 